\title{
Enric Miralles: espaciar el habitar. Multiplicación, fragmentación y diversificación del espacio medido a partir del ámbito
}

\author{
Elena Rocchi \\ Escuela de Diseño, Arizona State University, Estados Unidos \\ Recibido: 5 de septiembre del 2016 / Aprobado: 11 de diciembre del 2016
}

Este ensayo me ha permitido reflexionar sobre el espacio de la vivienda, es decir, sobre la técnica de diseño de la vivienda, mediante la representación de elementos fisicos y existenciales. Lo he hecho entrelazando mis reflexiones sobre el lugar en sí, mi experiencia profesional en el diseño de viviendas junto a Enric Miralles (seis viviendas en Ámsterdam, entre 1996 y 1998) y mi experiencia académica en la ESARQ UIC, Barcelona, en la NIROX Foundation de Johannesburgo y en la Escuela de Diseño de la Arizona State University, Tempe (desde 2008 hasta la fecha). Estas reflexiones evidencian la importancia que tienen en Miralles la dialéctica entre proyecto y dibujo, la relación entre la arquitectura interna-externa (lo fisico) y de lo que está dentro y fuera de cada uno de nosotros (lo existencial).

espacio, espaciar, pasajes, dibujo, geometría, habitar, ritual, habitación, esponjar

\section{Enric Miralles: Spacing the Dwelling. Multiplication, Fragmentation and Diversification of a Measured Space Based on the Site}

The essay proposed means to me the opportunity to think about the dwelling space understood as the housing design technique through the representation of physical and existential elements. I have done it by connecting my reflections on the site and the results of my professional experience in designing elaborated housings with Enric Miralles (6 housings in Amsterdam 1996/1998), and the results from another experience which took place during my academic experience celebrated both at the ESARQ-UIC, Barcelona, NIROX Foundation of Johannesburg and at ASU Design School, Tempe (from 2008 to date). These reflections make evident the importance in Miralles' architecture of dialectic in between design and drawing - between internal-external architecture (physical) and the interior and exterior of each of us (existential).

space, spacing, passages, drawing, geometry, live, ritual, room, fluff 


\section{LOS PASAJES}

\section{Inicio e interrupción de las habitaciones}

Los pasajes unen y separan las habitaciones. Son los elementos necesarios para recalcar las pausas y las repeticiones del acto de habitar. Es justo en los pasajes donde, al movernos de una habitación la otra, los sonidos, los rumores y los olores externos se entrometen como interferencias en el pensamiento continuo, como los blancos tipográficos en la escritura.

Paradójicamente, encerrados en las medidas fijas de nuestras habitaciones, nos extendemos, distendemos y reflexionamos a través de los pasajes. Porque el habitar no está hecho solo de formas, de medidas, de elementos temporales, de rituales, de interferencias, sino también de pasajes, lugares entre estancias donde espaciamos de forma mental la arquitectura fija de las habitaciones.

Para algunos arquitectos, la oportuna disposición de pasajes entre ambientes tiene la misma importancia que le dan algunos compositores a la disposición de tonalidades armónicas entre partes de una música coral. Comparemos por un momento el valor que un arquitecto como Enric Miralles le da a los pasajes de una vivienda con el valor que les da John Cage a las pausas de silencio entre los estilos musicales del experimento 44 Harmonies from Apartment House 1776. En ambos casos podríamos referirnos a los pasajes o a las pausas como al inicio e interrupción de piezas localizadas según coordenadas espacio-temporales propias de un apartamento que no se ve.Y recién entonces cabría imaginarse a Miralles como John Cage: en Manhattan, componiendo detrás de una ventana de su casa, en la esquina de la decimoctava y la sexta avenue, absorto, con la mirada en el vacío, indagando la música en los lugares del ruido, espaciándola con la mente, escuchando y observando la simultaneidad y la mezcolanza de ruidos de la humanidad, de ese tráfico siempre diferente, hecho de claxons, sirenas, voces, olores y luces... Imaginemos pues. 


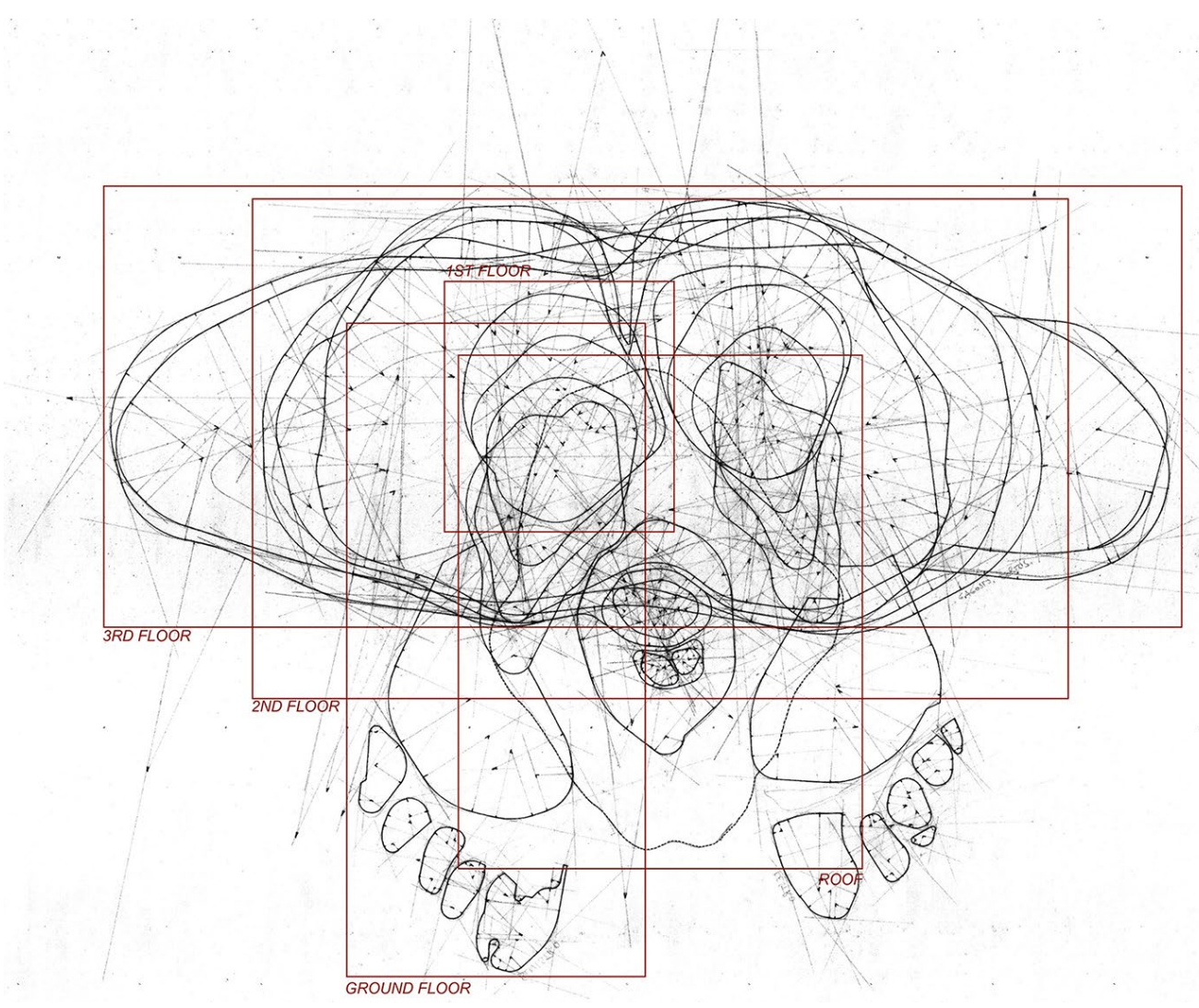

Figura 1

Dibujo a mano en tinta china

Antropomorfismo excavado. Este dibujo forma parte de un experimento sobre la representación del cuerpo "no visto" sino percibido desde adentro. Los participantes de un taller que conduje en la NIROX Foundation en 2012 se "registraron" según cinco secciones horizontales realizadas a la altura de los pies, de las rodillas, de la pelvis, de los hombros y de la cabeza. El dibujo de las plantas superpuestas revela que, cuando todo el cuerpo es achatado sobre un plano, se convierte en un cráneo que revela una geografía de lugares: rocas, llanuras, cavidades, canales, arcos, acueductos y columnas, todos dispuestos en un modo que mantiene, como observa Alberto Durero, una relación de similitud con la disposición simétrica del rostro, de los ojos, de la nariz, de la boca.

Elaboración propia 


\section{LOS FORMIDABLES PASAJES}

\section{La casa Mercaders y las lagunas como variaciones del habitar}

Como Cage, Miralles nos dice que habitar no es referirse al contenedor ni a las cosas contenidas, sino a la posición que estas ocupan en aquel. A inicios de los años noventa, junto a la arquitecta Benedetta Tagliabue, Enric proyectó su vivienda: la casa Mercaders, situada en el piso noble de un edificio del Barrio Gótico de Barcelona, cerca del mercado de Santa Catarina. Con el tiempo, debido al cambio de uso, esa casa había sufrido una transformación radical de los espacios típicos de una vivienda, ahora amalgamados en uno grande y único, sin aquellas divisiones que en el pasado habían delimitado las habitaciones que de alguna manera; sin embargo, aquellos espacios permanecían ahí, dibujados en el suelo, aún visibles en esos pisos silenciosos de losetas antiguas.

Enric y Benedetta decidieron habitar el apartamento tal como lo encontraron: un único gran ambiente dispuesto alrededor de un patio central en el que localizaron algunos pasajes como lagunas (lacunas en italiano), como espacios en blanco, a fin de iniciar e interrumpir los rituales del habitar. A partir del dibujo, tomaron, desprendieron y dispusieron las antiguas baldosas según nuevos pavimentos rectangulares fuertemente agarrados a las ventanas como para evitar caerse, desaparecer en la nada, según una forma modelada por el efecto de la luz cuando esta entra difusa y se hace visible sobre el piso, cuyos antiguos motivos florales insinuaban las sombras de unas cortinas que no se habían colgado todavía.

[Expandir] la experiencia de vivir entre habitaciones [y] rituales es [espaciar] el habitar a través de variaciones similares a las de los blancos tipográficos en los poemas mesósticos de Cage o a los silencios de su apartamento metafórico. 


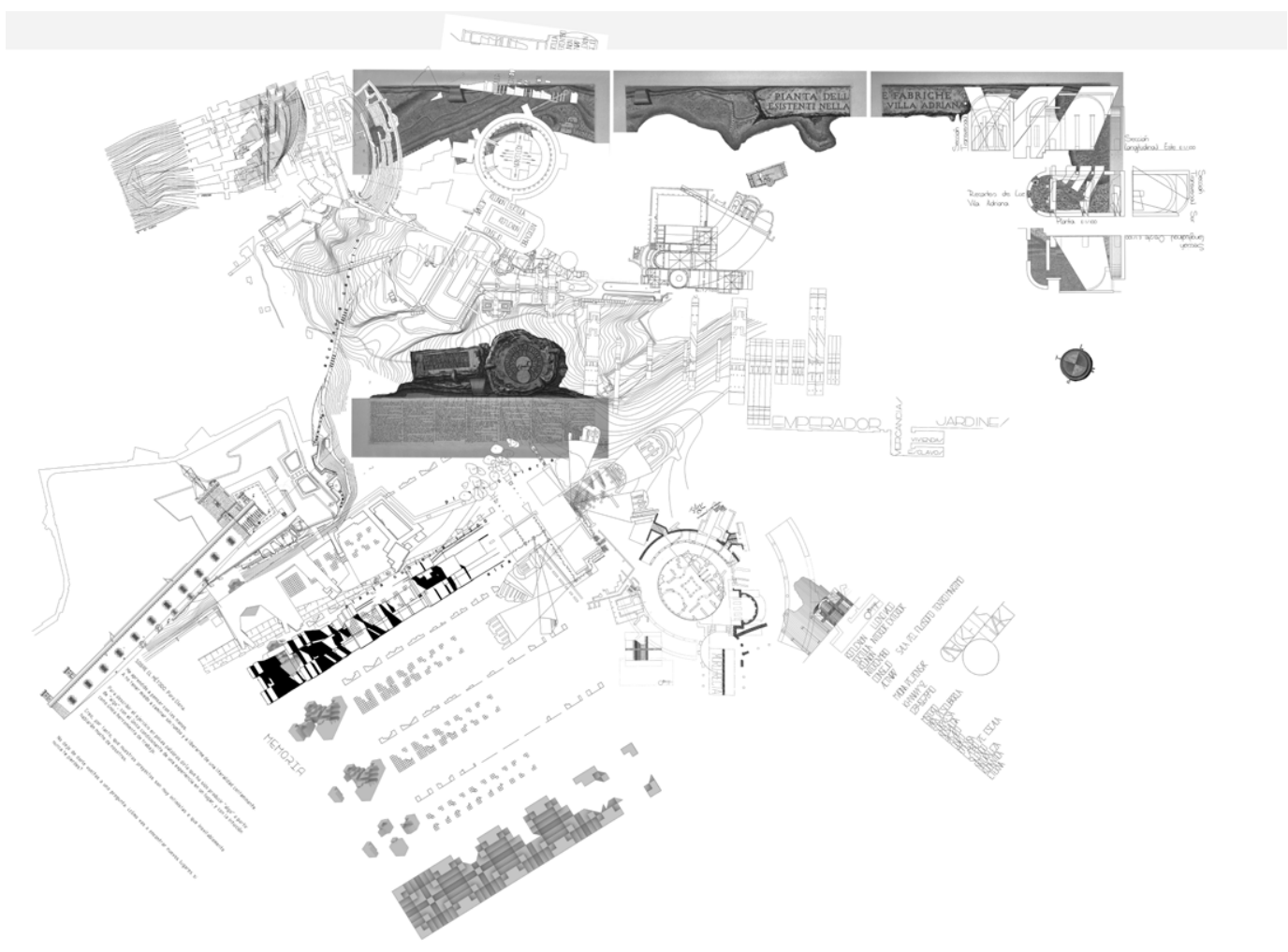

Figura 2

Dibujo en ordenador

Geografía habitada. Este dibujo es la suma de trabajos de los estudiantes de Arquitectura del $4 .^{\circ}$ año de la facultad ESARQ-UIC de Barcelona, de 2011. Al principio de curso, fuimos juntos a Roma y visitamos Villa Adriana, el ejemplo mas famoso de variaciones del habitar. Fue una especie de viaje iniciático para aprender a medir, registrar e interpretar los valores extraordinarios contenidos en una arquitectura doméstica hecha de habitaciones y de pasajes (lagunas). He compuesto este mapa con los fragmentos de la villa extraídos por los estudiantes en forma de apuntes transportados desde Roma hasta Barcelona como una forma de empezar a imaginar. Cada fragmento del dibujo es una mirada apoyada en una mítica geografía habitada.

Elaboración propia 


\section{OFICINA DEL SUPERINTENDENTE}

\section{Habitar el papel: mise en intrigue entre el espacio construido y el ámbito}

El dibujo en planta de la casa Mercaders es una de las mejores representaciones de la vivienda que conozco. Al igual que las 44 Armonías, refleja, por un lado, el espacio-tiempo de lo ocupado y, por el otro, el de las lagunas, de los vacíos, pasajes necesarios entre un ambiente y otro. El diseñar reveló al arquitecto que los momentos del habitar son todos igualmente importantes, inexorablemente mutables, ignotos, imprevisibles, inútilmente representables y que los pasajes entre habitaciones tienen la misma importancia que las habitaciones en las cuales "se está".

Miralles hablaba con frecuencia del espacio refiriéndose al volumen del aire de una habitación que alguien mueve al momento de atravesarla: se refería a la importancia del pasar a través de la habitación, no a la habitación. Como decía constantemente, no se fiaba del espacio y repetía una expresión catalana que rezaba: de l'espai no te'n refiis mai (del espacio no te fies nunca). Para él, organizar el espacio no significaba construirlo de acuerdo a las formas, sino de acuerdo a las experiencias, primera entre todas: la del dibujo. Pensaba la vivienda a partir del habitar el papel a través de la planta y la sección. Se tomaba todo el tiempo necesario para diseñar una habitación y después la otra, espaciándolas con grandes vacíos, las lagunas, la representación de esa "nada" a la cual todo se reduce y que él, como Cage, honraba. Espaciar el habitar, para Enric, sucedía rigurosamente siempre antes, en el proyecto (planta), y después en la realidad (maqueta) mediante la lenta disciplina de la geometría que obligaba al pensamiento a ser plano, a andar a pie por determinados espacios usando el lápiz, a moverse entre las puertas o hacia arriba por una escalera.

Es fácil imaginar esa primera vez que los arquitectos habitaron la casa Mercaders, según una conversación intermitente entre ellos mantenida a través de un dibujo a mano de la planta, en formato Din A0. Ese, todavía hoy, es un dibujo grande, vacío, lleno de los vacíos que corresponden cada vez que se apoya la mano sobre el papel al dibujar una habitación. Esta planta de la casa Mercaders es la representación de la experiencia de vivir la casa mientras se la dibuja, mientras se la habita con la mirada, con el 
pensamiento, con el deseo de esa vida que en ella sucederá. Uno empieza dibujando los ambientes de las futuras habitaciones e incluso, antes de ponerles estos o aquellos muebles, la vida ya ha sido imaginada durante todas las estaciones, de acuerdo a todos los humores y en varios estadios. La composición experimental de la planta Mercaders se centra ahí donde los pasajes comienzan y se interrumpen; revela el interés de Miralles por el habitar, entendido como situación laberíntica mental, por lo tanto, dilatada, no en la forma sino en la relación para nada continua entre los diferentes espacios, donde el único espacio que realmente importa es ese construido por la arquitectura y por el tiempo, en el que uno se encuentra "entre".

Un gran rótulo situado en la parte alta del dibujo revela que la planta no fue diseñada ni pensada según el norte, sino desde adentro, a partir de la experiencia que quizá tal vez se tuvo de esta: quizá desde el jardín, pero seguramente no desde la calle. Imaginemos. Alguien tomó el plano catastral del apartamento. Lo sujetó detrás de una hoja de papel vegetal y lo giró hacia sí mismo, desde donde estaba acostumbrado a comprenderlo, desde la puerta de casa ahí donde llegaba la escalera, o desde el jardín, con los pies bien puestos en la tierra y no flotando en el vacío sobre la otra parte de la calle.

La posición del estudio, en el medio, describe quién es el que está diseñando, desde adentro: el arquitecto-habitante. Porque de todas las ventanas del apartamento, la única representada en alzado lateral en la planta es justamente la de esta habitación, su estudio, volteada hacia el mundo exterior. Desde esa ventana, el arquitecto-habitante, como Cage, escucha. Observa los sonidos mientras dibuja. Se sienta de espaldas a la puerta y con la ventana a su derecha. Gira la cabeza y mira a través de ella: puede entrever el patio, la ventana que da a la entrada, la puerta del salón y luego, al fondo, la ventana que da al jardín, todo en la secuencia de una gran escorzo palladiano. Él se ha imaginado justo allí, sentado, porque las mejores casas son esas en las cuales las ventanas, como en las villas de Andrea Palladio, espacian la vista todavía más sobre otras que pertenecen a su vez a la misma casa. Luego, voltea la cabeza hacia la izquierda: distingue la otra puerta que da a la sala y luego la ventana que, finalmente, abre hacia la calle. 


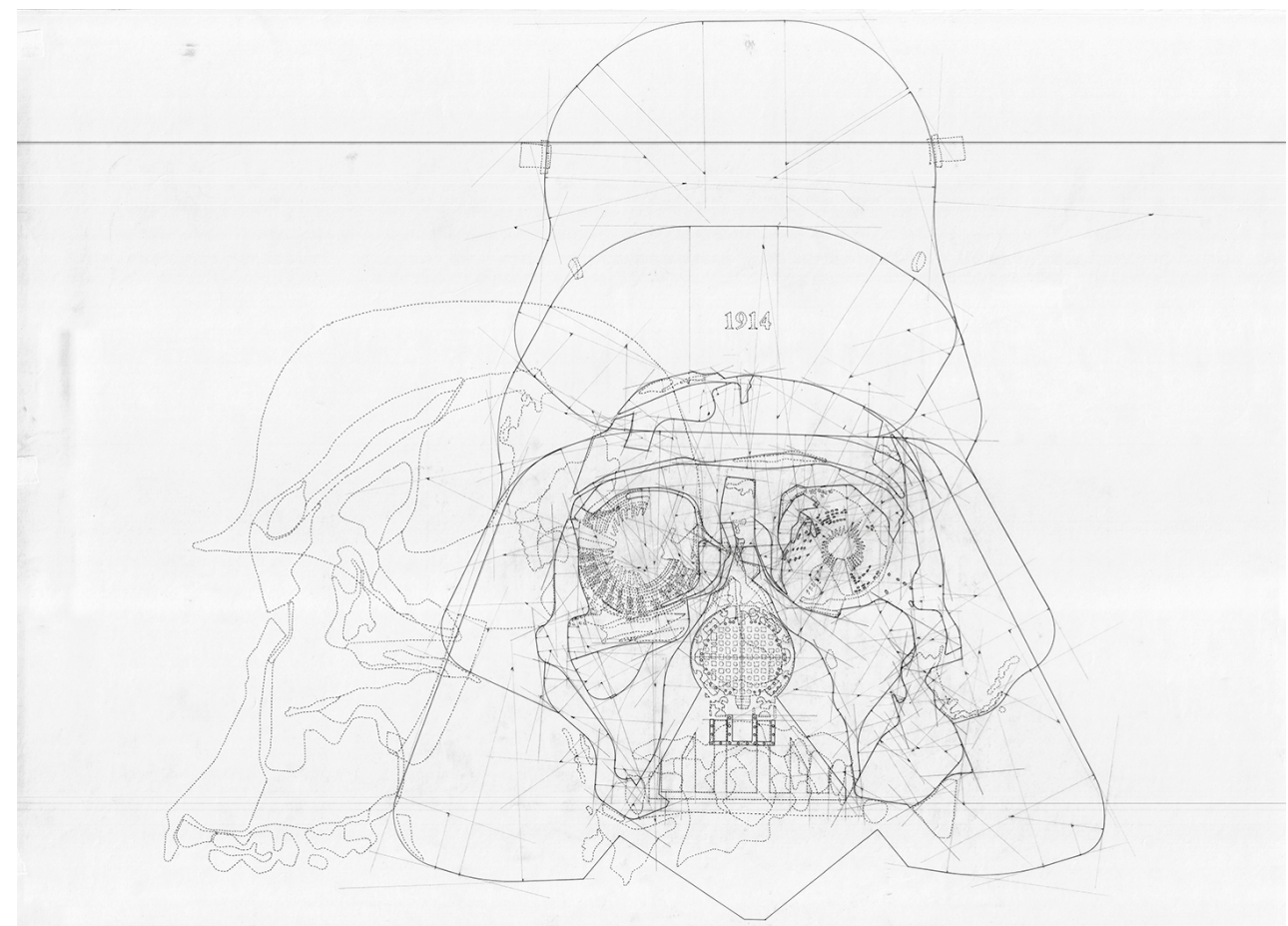

Figura 3

Dibujo a mano en tinta china

Darth Karabo. Este dibujo es un autorretrato excavado mientras se hace dibujando en el papel, y habitado con imágenes de interiores en lugar de los ojos, de la nariz y de la boca. Un autorretrato desde adentro, desde el cráneo, desde el recipiente en donde el cerebro, como un cartógrafo, produce mapas, incluso cuando dormimos.

Elaboración propia 


\section{LA LÁMINA}

\section{El espacio mental representado a través del drawing-through}

El espacio representado en la vivienda de la casa Mercaders es un espacio mental porque en esta planta uno no sabe cómo hacer para entrar, desde dónde tomar la escalera [[[[[]. La casa no tiene otro contexto que ella misma, volcada toda hacia [adentro] como la mente: todos están ya adentro, o nadie - ha entrado jamás. La única puerta diseñada volcada es esa de la entrada a la vivienda, que invade los últimos peldaños de la escalera: está caída sobre el rellano y lo invade mientras se resbala hacia abajo]]]]]. Todas las demás puertas están dibujadas cerradas, con movimientos ya dados o a punto de darse, sobre todo la primera que está frente a la puerta de entrada: esa de la habitación de los arquitectos-habitantes. Aparte de tres sillas Eames, una gran mesa, el piano, dos lámparas de mesa de Louis Polsen, no hay muebles, solo cosas aferradas a las paredes [ ] como aquellas lagunas lo están las ventanas [] [] [], protuberancias de la arquitectura necesaria: librerías, repisas, paredes móviles, clóset, camas.

Todo lo representado pertenece a la arquitectura, también las habitaciones dispuestas en los ángulos como en el tiro de esquina. Todo gira en torno a la gran nada del claustro central, describiendo como sobre una mesa una narrativa cageiana con "pausas", repeticiones, y silencios visuales: una mise en intrigue entre el espacio construido y el habitado, según una continuidad entre presencia y ausencia regulada por la geometría. Continuidad que Miralles traslada de una habitación a otra usando una sola plumilla $0,1 \mathrm{y}$ un solo tipo de tinta, dictada por el movimiento continuo de la mano, por la importancia que le da el proceso, por negarse a incluir en el dibujo cualquier elemento tridimensional de la realidad y por su consecuente disminución a un plan abstracto inmóvil, como si el dibujo fuera un momento cero, un instante muerto en el fluir de la vida, donde los rituales, componentes fundamental en variación continua, no se pueden representar. Tal vez sea una multiplicidad a lo Cage, hecha plana y por lo tanto, vacía, compuesta según ese principio espacio-temporal de experimentación a través de un material como proceso de proyección, de drawing-through. 


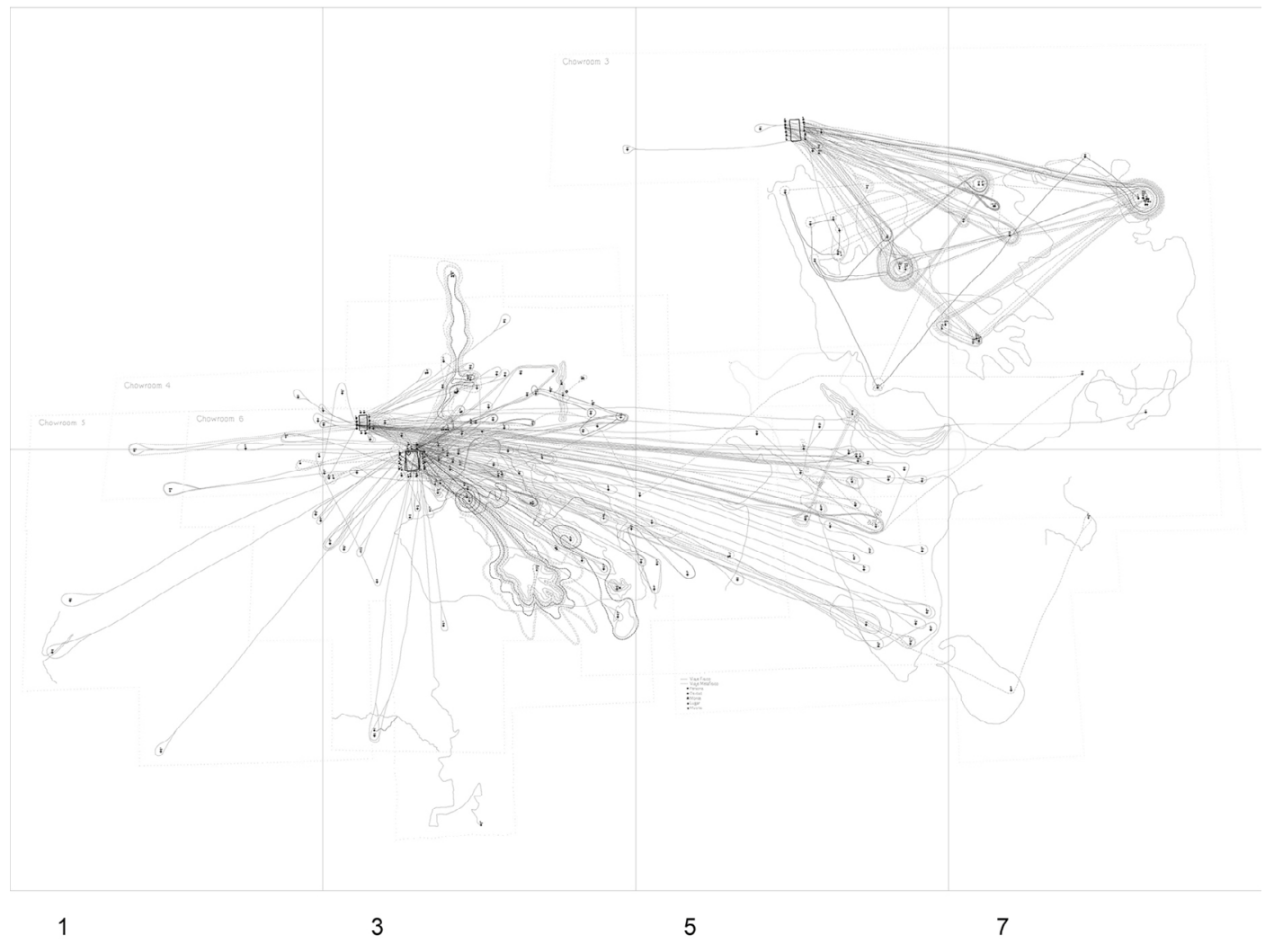

Figura 4

Dibujo en computadora

Este dibujo es el resultado de un experimento que he desarrollado en Barcelona durante una serie de seis cenas, entre el 2010 y el 2011, y que presenté en junio del 2013 en la galería de arquitectura OAB, de Carlos Ferrater. Cada cena fue concebida como una performance. Un personaje experto en algo y doce comensales compartían el espacio de una mesa durante la cena. Los cuerpos convergían en el del protagonista encargado de activar su imaginación para transferirla dentro del ámbito de una memoria personal. Este dibujo es la representación de las seis mesas y de los lugares mentales adonde los comensales y el invitado viajaron estando cómodamente sentados.

Elaboración propia, en colaboración con Nacho Vallhonrat 


\section{LA VIVIENDA ESPONJADA}

La concepción simultánea de seis viviendas en Ámsterdam y la modificación del PERI, Plan Especial de Reforma Interior de la Ciutat Vella, Barcelona

En 1996, al recibir el encargo para el proyecto de seis viviendas en el vecindario de Borneo Einland, en Ámsterdam, Miralles y Tagliabue volvieron a reflexionar sobre la vivienda. El proyecto formaba parte de un plan maestro redactado por West 8 para construir 2500 viviendas concebidas como la reinterpretación contemporánea de la casa holandesa tradicional. El carácter distintivo de estudios como los de OMA, MVRDV, UN Studio y Neutelings Riedijk dio origen a distintas variantes arquitectónicas en la investigación de nuevas formas de habitar que, colocadas todas juntas, crearon un collage de colores típicos de los pequeños pueblos tradicionales holandeses, como los pintados porVermeer. Miralles decidió esta vez trabajar de un modo mucho más intuitivo, a partir de la concepción abstracta del plan maestro y de las condiciones habitacionales propias de las tipologías alargadas de la tradición holandesa, organizadas a lo largo de los canales en extensas secuencias de casas adosadas. Una casa larga de $24 \mathrm{~m}$ entre calle y calle, con un ancho de 3,5 $\mathrm{m}$ en el frente y 4,5 $\mathrm{m}$ en la parte de atrás fue la base de la propuesta tipológica para las seis casas, concebida como una única gran habitación en la que una escalera interior era el pasaje obligado que la espaciaba, moviéndose desde el acceso, en la parte central de la planta baja, hacia el frente y después hacia atrás, de abajo arriba. Al hacerlo, Miralles delegaba a la escalera la organización de los espacios y de los rituales. El proyecto, uno de los últimos del estudio en ser diseñado completamente a mano, comenzó durante la mudanza del despacho de la calle Avinyó al Passatge de la Pau.

En ausencia de un lugar donde diseñar, Miralles trabajó en dos proyectos desde aquella habitación situada al medio de su casa: el de Ámsterdam y el del mercado de Santa Caterina (modificación del Plan Especial de Reforma Interior [PERI]). Ambos proyectos cohabitaron y se espaciaron el uno dentro del otro. Mientras Miralles diseñaba las seis casas desde la suya, oía los ruidos de fondo de unas demoliciones en esta parte oriental del centro histórico de Barcelona: sucedían en 1996, tal como lo había previsto el plan vigente del PERI de 1979. Estas duraron casi un año y produjeron un escenario 
similar al fotografiado en Beirut por Gabriele Basilico en 1991, después de quince años de guerra: ese de un sitio arqueológico urbano hostigado por mutilaciones sustanciales y recientes, hechas a la carrera y justificadas como recalificación urbana que desfiguraba el tejido medieval para hacerle sitio a nuevas viviendas sin consideraciones tipológicas.

Las demoliciones hicieron visibles varios de los interiores secretos, procesos del tiempo a los cuales ese pedazo de ciudad había estado sometido, pasajes entre las diversas manos de los propietarios, fragmentaciones internas debidas a la sucesión de generaciones. Vista en sección, esa parte de ciudad parecía de repente una gran y única vivienda hecha de unidades simples ahora puestas todas juntas como una gran casa en la cual se hacían visibles con pudor los baños, las cornisas todavía colgadas de los muros, los mosaicos de losetas con los caños suspendidos en el vacío, las construcciones ilegales, los rastros de escaleras, pero también las estructuras ruinosas, la decadencia, la pobreza y el abandono de los años. Disonancias que la demolición descubría y reestructuraba según un gran alzado, como la composición de Cage hacía con las 44 Armonías. Fue en ese escenario y en aquel de su propia casa que Miralles experimentó el diálogo con las disonancias temporales. Lo hizo sin desmantelar o desentrañar desde afuera, sino estando adentro y por medio del uso de la geometría. Esta experiencia lo guió a la redacción de la modificación del plan vigente del PERI para la abertura de la Porta Cambó, que le encargó el municipio: por un lado, propuso aligerar sustancialmente el volumen de demoliciones requeridas por el plan abstracto, y por el otro, proyectó un plan maestro habitacional, en el cual la nueva arquitectura funcionara como contrafuerte de las amputaciones supérstites, y como consolidación del momento de la reconciliación que se hacía visible en la Porta Cambó. 


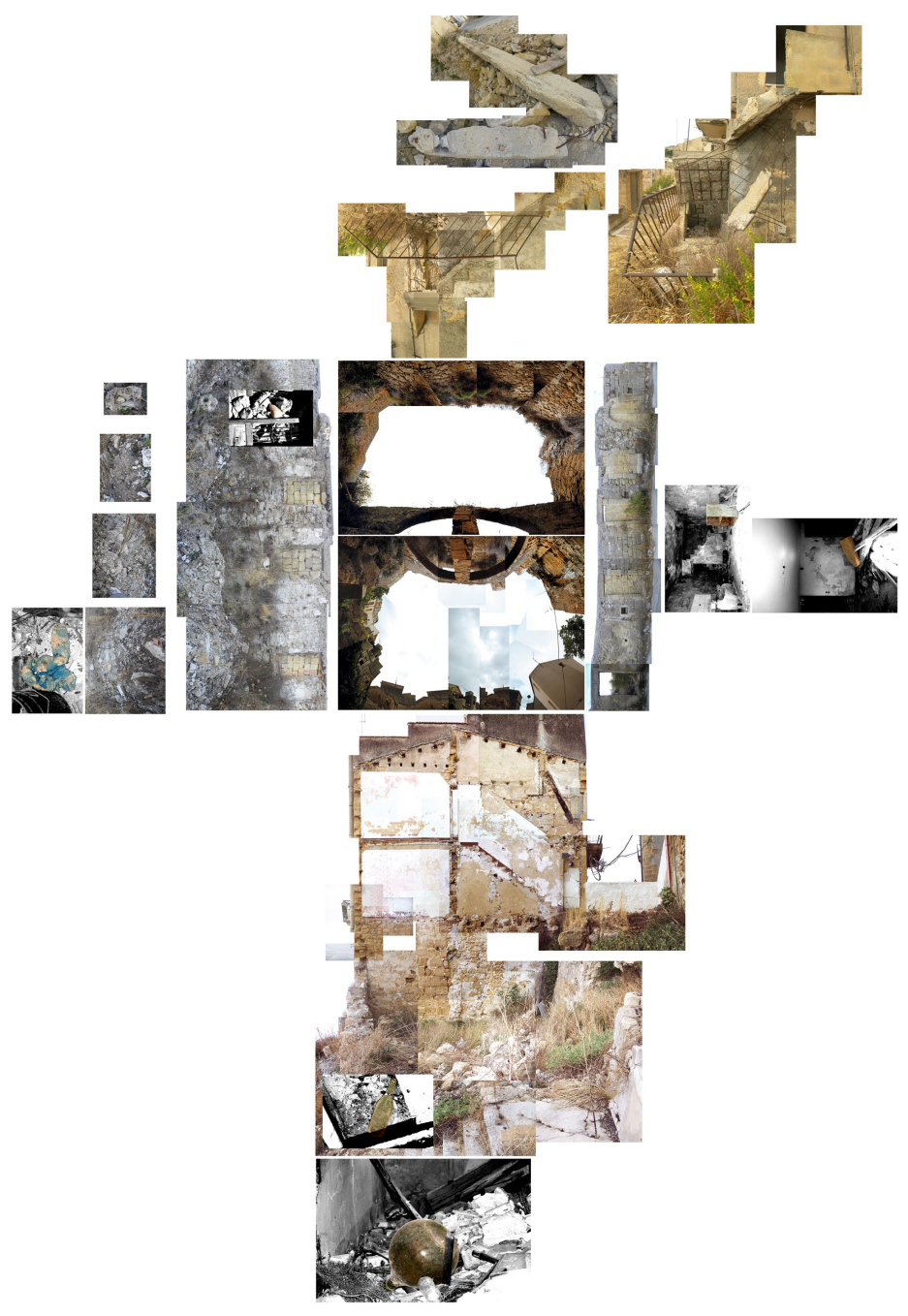

Figura 5

Collage fotográfico

Este documento recoge las huellas de una casa destechada por un terremoto; las conserva y las relaciona según una pasividad entendida como un rol activo del silencio y del vacío del lugar del muerto. El registro de un instante como el de un corte en el continuum en el cual se hace visible el final mismo. Elaboración propia 


\section{LA HABITACIÓN VACÍA}

Ese escenario de disonancias temporales poco a poco condujo a Miralles a la propuesta para el proyecto de Ámsterdam. Intercalado en la secuencia del layout de esas seis casas de Ámsterdam, la planificación de Adriaan Geuze había previsto originalmente un pasaje de una calle para cruzar trasversalmente el vecindario: Miralles lo integró en el proyecto, en el sentido de espacio rescatado de la demolición imaginada en el dibujo de una casa, un vacío generado por una extracción. Una especie de casa vacía, muy similar en alzado a uno de esos interiores descubiertos por las demoliciones visibles acústicamente desde su casa mientras estaba totalmente absorto en el dibujo. Miralles realizó en el proyecto de Ámsterdam una especie de esponjamiento conceptual que, interpuesto en la larga fila de casas adosadas, cumplía ambos requisitos dispuestos por Geuze a cada arquitecto para alcanzar la calidad arquitectónica/tipológica de las casas y su inserción en un contexto de agua. El proyecto de Miralles se encontraba justamente en el lote destinado al pasaje por el que transitaban obligatoriamente las personas "desde la naturaleza al habitar”. En aquella especie de casa vacía, Miralles construyó la dilatación de una experiencia espacio-temporal construyendo a escala reducida una puerta (similar a esa de la avenida Cambó en Barcelona), como un pasaje entre casas demolidas, ahora todas volteadas hacia afuera por el esponjamiento, como los bolsillos de una chaqueta de segunda mano.

Miralles simuló esa demolición a partir de esponjar su propio dibujo, hipotetizando el retiro de una casa y su traslación sobre la del costado: un proceso de demolición que construye a través del dibujo. Lo hizo, presumiblemente, conforme a este razonamiento visible en los croquis iniciales: dispuso en modo abstracto las seis viviendas entre el proyecto de De Architectengroep y el de Kees Christiaanse, para completar la larga muralla de casas; extrajo entonces una vivienda y, disponiéndola sobre la del costado, simuló un ulterior gesto de las manos como para abrir esa fisura un poco más. A través del dibujo, simuló el tiempo de la arquitectura construyendo la densidad de la ciudad y al mismo tiempo, su esponjamiento: usó la simulación de la planificación como instrumento para espaciar el proyecto. El pasaje, la casa vacía, dibuja la transición entre lo externo de la ciudad, bien compuesto y controlable en perspectiva de los habitantes, y el interior, entendido como lugar de la experiencia del habitar: un pasaje que espacia la vivienda, no desde adentro 
sino desde afuera; un pasaje obligado entre casa y casa que asume la misma importancia que la casa misma, el generador de esa "sublime continuidad" entre interior y exterior, a la cual se refería Geuze todo el tiempo.

Esta casa vacía en Amsterdam es hoy el recuerdo del espacio en el devenir de la destrucción en Barcelona, derivado e injertado para cuestionar el estado homogéneo y monolítico de la planificación abstracta de la cual deriva, para descomponerla, degradarla, fragmentarla. Una especie de objeto indefinido producido en Barcelona casi según un proceso fisiológico natural aprendido con el proyecto de la casa Mercaders y con las demoliciones del PERI, e introducido entre las seis casas en Ámsterdam para contagiar la abstracción de la planificación que lo ha generado, así como hacen las personas cuando rectifican la arquitectura al habitarla, o los ruidos del tráfico cuando invaden la vida privada de un loft en Nueva York, como decir que la perfección abstracta no es el objetivo último de la arquitectura, porque la condición de ruina habita en la estructura misma de la arquitectura. Al pasar por el medio de esta especie de casa vacía se observan algunos fragmentos de vida: patterns de ladrillos que simulan un alzado de habitaciones separadas por un tabique o las líneas de una viga en ángulo de una escalera en hormigón armado. Estos fragmentos hablan de modo elocuente de la ausencia de una casa cuya totalidad ha quedado vacía.

Los alzados en el vano del pasaje se dibujaron usando como referencia la imagen de la demolición en Barcelona, impresa en la mente, oída a través de la ventana del estudio de la casa Mercaders. Con frecuencia, observando esos edificios desfigurados imaginábamos las partes sustraídas, reflexionábamos sobre la construcción/destrucción, como hace Gordon Matta-Clark cuando deja que el esponjamiento se haga nuevamente construcción: entonces, el proyecto para las viviendas de Ámsterdam es un proyecto basado en la destrucción creativa en el cual la totalidad ausente de la "casa vacía" reconstruye, racionalizándolo, el esponjamiento de la Porta Cambó. 

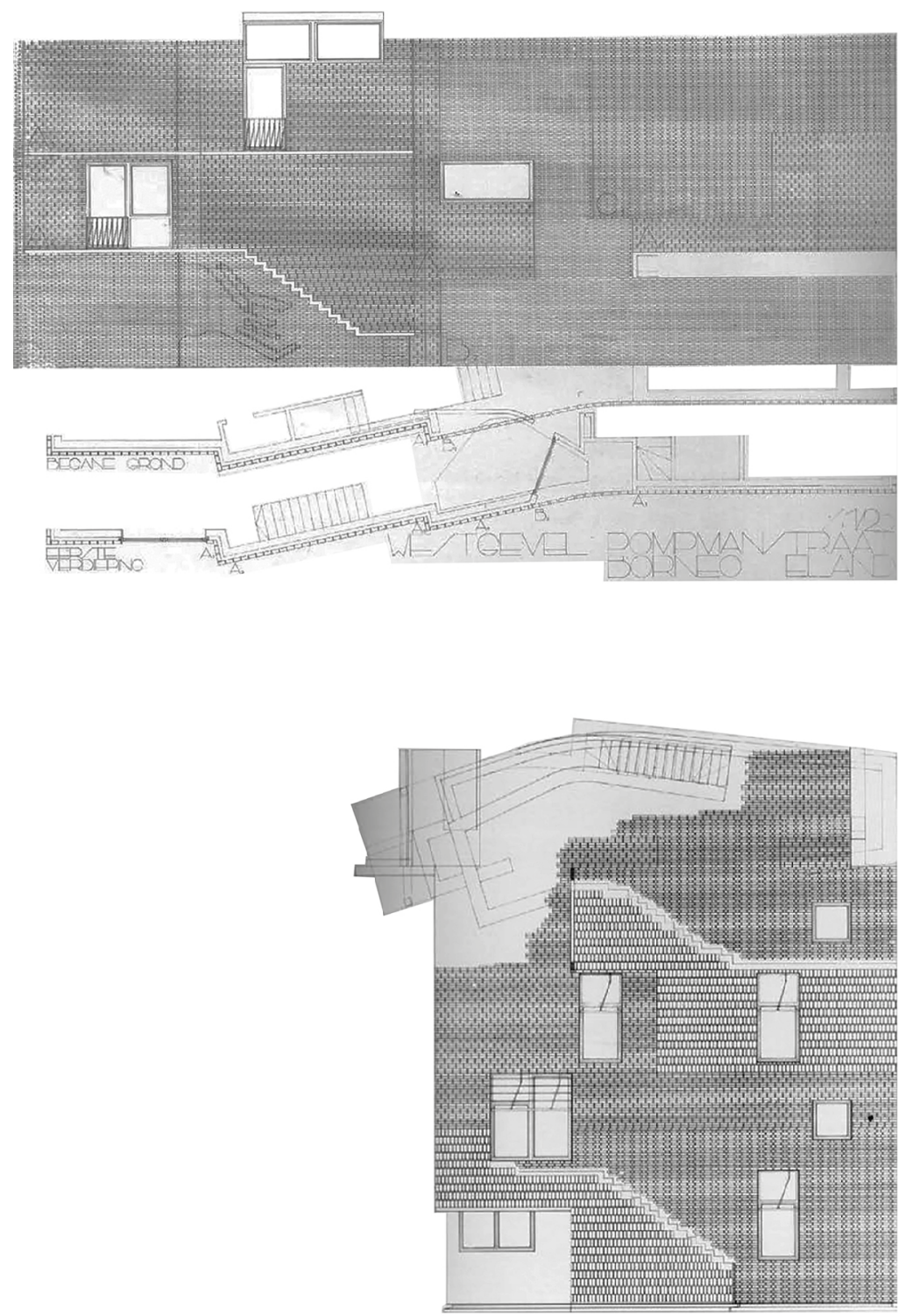

Figura 6

Dibujo a mano en tinta china. Proyecto para seis casas en Ámsterdam, de EMBT Arquitectes Associats Dibujo a mano de Elena Rocchi de los alzados de la "casa vacía" en el proyecto de EMBT, Borneo Eiland, Ámsterdam 1996

Elaboración propia 


\section{MISE EN INTRIGUE}

\section{Ámbito y espacio medido}

Habitar es entonces conversar con el espacio que la arquitectura circunscribe. Un espacio donde nuestras historias afloran y se convierten en parte de una historia más grande. Como arquitectos, nos encargamos de proyectar viviendas, de cuantificar y medir geométricamente el espacio, no de humanizarlo (en el sentido de habitarlo). Pero hay arquitectos que, a través de la representación, simulan la humanización de las viviendas como técnica de proyecto de estas. Lo hacen tejiendo una mise en intrigue (una estructura narrativa) entre el ámbito (actitud en el espacio) y el espacio arquitectónico (espacio medido). Enric Miralles era uno de estos arquitectos expertos en espaciar la vivienda a la manera de Cage, a partir de la representación de pasajes/pausas como inicio e interrupción de unas piezas localizadas según coordenadas espacio-temporales propias de un apartamento que se ve y no se ve. En el proyecto para su residencia en el centro histórico de Barcelona, como para las seis casas en Ámsterdam, Miralles multiplicó, fragmentó y diversificó los espacios medidos del habitar, a partir de sus actitudes, de cómo vivía y se movía de un espacio al otro de la arquitectura y del papel en el que diseñaba, simulando una mise en intrigue entre determinados elementos físicos diseñados simultáneamente en la planta y en alzado como formas de devolver y comprender situaciones existenciales sobresalientes. Usaba un procedimiento geométrico informal con el objetivo de fijar los espacios; por una parte, indagaba sobre cómo liberar la vivienda de las restricciones tipológicas tradicionales introduciendo nuevos rituales/ámbitos en edificios antiguos; por otra parte, proyectaba la vivienda a partir del habitar el papel como una manera de educarse a si mismo y a sus proyectistas sobre la actitud de habitar antes que nada el documento de arquitectura.

"Espaciar" el habitar es producir la vivienda partiendo de la representación de elementos fisicos y existenciales, del proceder del propio cuerpo, entendido como mente, en el paisaje, desde la propia cama a la ciudad, desde detrás de una ventana a la esquina entre la decimoctava y la sexta avenue, absorto con la mirada en el vacío, mientras, indagando los lugares de los pasajes uno experimenta acerca de la importancia del proyectar, de la dialéctica entre lo interior y lo exterior de la arquitectura (lo físico) con eso que está dentro y fuera de cada uno de nosotros (lo existencial). 


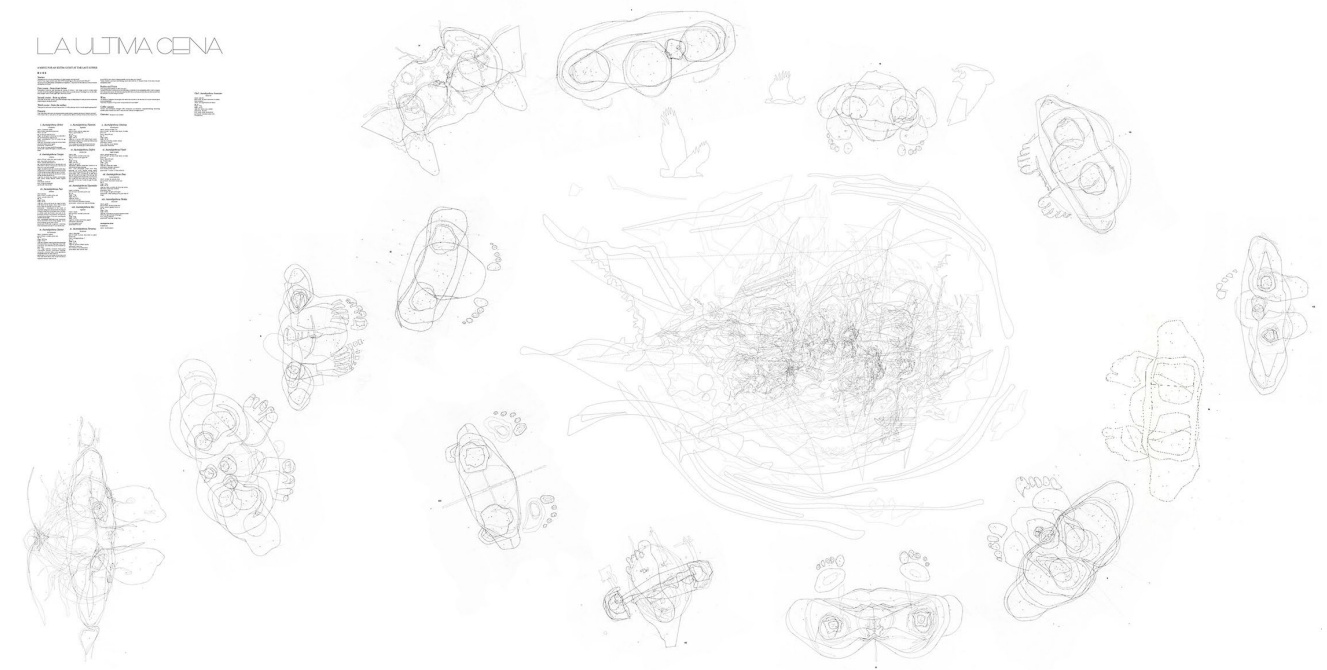

Figura 7

Dibujo a mano en tinta china

La última cena. Una serie de cuerpos distintos, como tonalidades armónicas de una música coral, convergen en este documento. Cuerpos únicos e individuales, originalmente dibujados de modo separado (dibujo 1) y asociados de una manera que activa una mise en intrigue.

Elaboración propia 